\title{
Os Direitos dos Trabalhadores em tempos de pandemia
}

\section{Fundamental Rights of Workers in pandemic times}

\author{
Leda Maria Messias da Silva ${ }^{1}$
}

Ana Paula Dalmas Rodrigues ${ }^{2}$

\section{RESUMO}

No atual cenário jurídico doutrinário muito se fala em direitos fundamentais e garantias constitucionais. Nessa temática, serão abordados conceitos, requisitos e a efetividade dos direitos fundamentais sobre a ótica de Sarlet, Alexy e Hesse. Em tempos de pandemia, as relações de trabalho estão sendo relativizadas e sendo alvo de inúmeras medidas provisórias, tendo em vista a especificidade do momento excepcional. No entanto, a relativização/ precarização também pode ser observada com o advento da reforma trabalhista de 2017. Sendo assim, o artigo pretende analisar se as legislações trabalhistas estão em consonância com os direitos fundamentais catalogados na Constituição Federal. Em que pese à garantia constitucional do salário mínimo, este deixa de ser observado ao trabalhador intermitente, o que viola preceitos constitucionais. A pesquisa será teórica, método exploratório e descritivo para abordagem do tema.

\section{PALAVRAS-CHAVE:}

Direitos fundamentais. Relações de trabalho. Pandemia.

\begin{abstract}
In the current legal doctrinal scenario, much is said about fundamental rights and constitutional guarantees. In this theme, concepts, requirements and the effectiveness of fundamental rights from the perspective of Sarlet, Alexy and Hesse will be addressed. In times of pandemic, labor relations are being relativized and are the target of numerous provisional measures, in view of the specificity of the exceptional moment. However, the relativization / precariousness can also be observed with the advent of the labor reform of 2017. Therefore, the article intends to analyze whether the labor laws are in line with the fundamental rights cataloged in the Federal Constitution. In spite of the constitutional guarantee of the minimum wage, this is no longer observed for intermittent workers, which violates constitutional precepts. The research will be theoretical, exploratory and descriptive method to approach the theme.
\end{abstract}

\footnotetext{
${ }^{1}$ Pós-doutorado em Direito do Trabalho, pela Universidade de Lisboa-Portugal (2012); doutorado em Direito pela Pontifícia Universidade Católica de São Paulo (2004); mestrado em Direito pela Pontifícia Universidade Católica de São Paulo (1995) e graduação em Direito pela Fundação Universidade Estadual de Maringá (1986); professora do Programa em Ciências Jurídicas da Universidade Unicesumar e da Universidade Estadual de Maringá-PR; pesquisadora do Instituto Cesumar de Ciência, Tecnologia e Inovação, bolsista de produtividade em pesquisa do ICETI e integrante de grupo de pesquisa junto ao CNPQ.

2 Mestranda em Ciências Jurídicas pelo Centro Universitário de Maringá - UNICESUMAR; Especialista Lato Sensu em Direito do Trabalho pela Associação dos Magistrados Trabalhistas da $23^{\text {a }}$ Região; Professora nos cursos de graduação em direito da Universidade do Estado de Mato Grosso e Faculdade do Pantanal;
} 


\section{KEYWORDS:}

Fundamental rights. Work relationships. Pandemic.

\section{INTRODUÇÃO}

Em tempos de pandemia pelo novo coronavírus que assola o Brasil e o mundo, desde o final do ano de 2019, as relações trabalhistas estão sendo altamente atingidas, assim como áreas sociais, econômicas, culturais, psicológicas, dentre outras.

Muito antes da pandemia, desde a reforma trabalhista publicada em novembro de 2017, as normas incidentes nas relações de trabalho trouxeram para o ordenamento jurídico pátrio uma nova modalidade de contrato de trabalho, o intermitente. $\mathrm{O}$ artigo $443, \S 3^{\circ}$ da Consolidação das Leis Trabalhistas, retrata que quando a prestação de serviço se dá de forma subordinada, no entanto, com alternância de períodos de trabalho, considera-se trabalho intermitente.

A Lei faz uma ressalva que, com exceção dos aeronautas, todas as demais atividades desenvolvidas pelos empregadores são compatíveis com essa modalidade contratual. Isso significa dizer que o contrato de trabalho intermitente já é uma realidade no nosso país e pode ser utilizado quase que indistintamente.

Dado esse aporte introdutório a respeito do tema a ser pesquisado, importa frisar a correlação desse novo trabalhador criado em novembro de 2017, bem como os novos ajustes do contrato de trabalho em tempos de pandemia, com os direitos fundamentais definidos pelo constituinte originário.

O artigo pretende trazer uma reflexão de direitos fundamentais sobre as teorias encampadas por Sarlet, Alexy e Hesse. Em que pese haja um vácuo temporal entre os juristas alemães, Konrad Hesse (1919-2005) e Robert Alexy (1945), ambos compartilham de alguns entendimentos comuns sobre os direitos fundamentais que serão trazidos ao debate. Em reforço, 
Ingo Sarlet (1963), também os cita em sua obra, A "Eficácia dos Direitos Fundamentais", fazendo um contraponto entre as ideias dos três autores.

Abordadas as características dos direitos fundamentais e, principalmente, a força normativa, serão tratados dos direitos da personalidade. Para o debate serão trazidos autores contemporâneos que já defendem os direitos da personalidade na teoria pluralista.

Um paralelo deve ser traçado entre os direitos fundamentais e os direitos da personalidade dos trabalhadores "criados" pela reforma trabalhista e pela flexibilização das normas trabalhistas em tempo de pandemia. Indaga-se o fato do legislador inserir novos preceitos inerentes à relação de trabalho em consonância ou não com os direitos fundamentais estabelecidos na Constituição de 1988.

$\mathrm{O}$ argumento de que os direitos trabalhistas impactam nos aspectos econômicos do país não merece atenção, haja vista a proteção constitucional e fundamental dos direitos trabalhistas no ordenamento jurídico vigente. A “contrario sensu” seria possível dizer que os autores constitucionais supracitados estariam ultrapassados e suas teorias deveriam ser abandonadas, validando assim a norma infraconstitucional, mesmo que traga violações constitucionais.

Tais debates merecem a reflexão que o texto pretende fazer, utilizando como método a pesquisa bibliográfica, consultando autores constitucionais clássicos como Ingo Sarlet, Konrad Hesse e Alexy para argumentar sobre a efetividade e a força normativa da Constituição Federal. Posteriormente, com a abordagem descritiva e exploratória, serão tratados aspectos específicos das novas legislações frente à pandemia do novo coronavírus.

\section{OS DIREITOS FUNDAMENTAIS}

Alguns critérios tentam definir o que são direitos fundamentais, do ponto de vista histórico (...). O que parece fundamental numa época histórica e numa determinada civilização não é fundamental em outras épocas e em outras culturas. (BOBBIO, 1909, p.13). Ou seja, a característica fundamental do direito decorre do momento histórico. Nesse sentido, se fala em 
direito fundamental à água potável, por exemplo, como decorrente do momento atual em que a sociedade vive.

Para além do aspecto classificatório em razão do momento histórico, entende-se por fundamentais os direitos catalogados na Constituição Federal, no título II, denominado dos direitos e garantias fundamentais, vejamos:

\begin{abstract}
Outro aspecto a ser considerado, de modo especial no caso brasileiro, é a extensão do catálogo dos direitos fundamentais (individuais e sociais), que recomenda - para além dos motivos já ventilados - extrema cautela na busca de outros direitos substancialmente equivalentes, inclusive para evitar uma vulgarização da categoria dos direitos fundamentais, que devem integrar o núcleo material da Constituição. Aqui assume particular relevo o critério já referido da equivalência, seja no que diz com o conteúdo, seja no que tange à importância de determinada matéria para o sentimento jurídico dominante em dado momento histórico. (SARLET, 2012, p. 106)
\end{abstract}

Na visão de Ingo Sarlet, tudo aquilo que esteja no catálogo constitucional é considerado como direito fundamental. No entanto, é preciso ter cuidado para não chegarmos ao estado de vulgarização dos direitos fundamentais, sobretudo, pelo excesso de direitos catalogados sem se atentar a essencialidade do direito sobre a ótica do núcleo essencial.

Alinhada a essa crítica do autor pelo excesso de direitos fundamentais, cita-se alguns artigos vinculados ao Direito do Trabalho que não teriam razão para estar no catálago, na visão do autor, e, por consequência, ser considerados como direitos fundamentais.

Também no elenco dos direitos individuais e coletivos do art. $5^{3 \mathrm{o}}$, bem como no rol dos direitos sociais (arts. $6^{\circ}$ a 11 ), se detectam dispositivos de fundamentalidade material no mínimo controversa, tais como o art. $5^{\circ}$, incs. XXVIII e XXIX ${ }^{4}$, bem como o art. $7^{\circ}$, incs. XI e XXIX ${ }^{5}$, além de alguns dos incisos do art. $8^{\circ}$, que versa sobre a liberdade de associação sindical. São dispositivos que, sem dúvida, não guardam relação direta com a proteção da dignidade humana ou que decorram de forma inequívoca dos princípios e do regime da nossa Constituição como posições essenciais

\footnotetext{
${ }^{3}$ Art. $5^{\circ}$ Todos são iguais perante a lei, sem distinção de qualquer natureza, garantindo-se aos brasileiros e aos estrangeiros residentes no País a inviolabilidade do direito à vida, à liberdade, à igualdade, à segurança e à propriedade, nos termos seguintes:

${ }^{4}$ XXVIII - são assegurados, nos termos da lei:

a) a proteção às participações individuais em obras coletivas e à reprodução da imagem e voz humanas, inclusive nas atividades desportivas;

b) o direito de fiscalização do aproveitamento econômico das obras que criarem ou de que participarem aos criadores, aos intérpretes e às respectivas representações sindicais e associativas;

XXIX - a lei assegurará aos autores de inventos industriais privilégio temporário para sua utilização, bem como proteção às criações industriais, à propriedade das marcas, aos nomes de empresas e a outros signos distintivos, tendo em vista o interesse social e o desenvolvimento tecnológico e econômico do País;

${ }^{5}$ XI - participação nos lucros, ou resultados, desvinculada da remuneração, e, excepcionalmente, participação na gestão da empresa, conforme definido em lei;

XXIX - ação, quanto aos créditos resultantes das relações de trabalho, com prazo prescricional de cinco anos para os trabalhadores urbanos e rurais, até o limite de dois anos após a extinção do contrato de trabalho;
} 
do indivíduo na sua dimensão individual e social. Em suma, cuida-se de normas que não se enquadram nos parâmetros (reconhecidamente empíricos e elásticos) traçados para a identificação dos direitos materialmente fundamentais, muito embora não estejam em discussão a importância da matéria (ao menos no que diz com alguns dos dispositivos) e a pertinência de sua previsão na Constituição formal com o objetivo de evitar sua disponibilidade ampla por parte do legislador ordinário. Não se poderá deixar de considerar que incumbe ao Constituinte a opção de guindar à condição de direitos fundamentais certas situações (ou posições) que, na sua opinião, devem ser objeto de especial proteção, compartilhando o regime da fundamentalidade formal e material peculiar dos direitos fundamentais. (SARLET, 2012, p. 105)

Todavia, há o reconhecimento de que o constituinte elevou ao nível de direitos fundamentais os direitos trabalhistas, para que o legislador ordinário não fosse capaz de limitar ou suprimir tais direitos, dando o aspecto de direitos formalmente constitucionais, em que pese aos olhos de Sarlet, não sejam materialmente fundamentais. Neste item, é importante fazer uma reflexão se a reforma trabalhista, bem como as legislações da pandemia, observaram os aspectos de direitos fundamentais ou se limitaram/violaram, via lei ordinária, direitos que já se encontravam salvaguardados pelo constituinte originário.

O fato de elevar um direito ao nível de direito fundamental, como os direitos trabalhistas, inserindo-os no catálogo constitucional, importa em dar eficácia irradiante aos direitos fundamentais, no sentido de que estes, fornecem impulsos e diretrizes para a aplicação e interpretação do direito infraconstitucional, e a necessidade de uma interpretação conforme aos direitos fundamentais, que, ademais, pode ser considerada - ainda que com restrições - como modalidade semelhante à difundida técnica hermenêutica da interpretação conforme à Constituição. (SARLET, 2012, p. 128)

\begin{abstract}
Outra importante função atribuída aos direitos fundamentais e desenvolvida com base na existência de um dever geral de efetivação atribuído ao Estado, por sua vez agregado à perspectiva objetiva dos direitos fundamentais, diz com o reconhecimento de deveres de proteção (Schutzpflichten) do Estado, no sentido de que a este incumbe zelar, inclusive preventivamente, pela proteção dos direitos fundamentais dos indivíduos não somente contra os poderes públicos, mas, também contra agressões provindas de particulares e até mesmo de outros Estados. Esta incumbência, por sua vez, desemboca na obrigação de o Estado adotar medidas positivas da mais diversa natureza (por exemplo, por meio de proibições, autorizações, medidas legislativas de natureza penal etc.), com o objetivo precípuo de proteger de forma efetiva o exercício dos direitos fundamentais. (SARLET, 2012, p.128)
\end{abstract}

Assim, os deveres de proteção não constituem - na dicção de Gomes Canotilho - "um simples dever de acção do Estado para proteger bens ou promover fins constitucionais, mas de um dever de acção para 'segurar' direitos consagrados e protegidos por normas constitucionais”. (SARLET, 2012, p.129) 
Já que os direitos fundamentais estão catalogados, não cabe ao legislador infraconstitucional discutir sobre a sua essencialidade. O Estado agora tem o dever de proteção, e, mais do que isso, deve agir para assegurar a efetividade de tais direitos. Nesse sentido, o Supremo Tribunal Federal foi provocado com a propositura de trinta e quatro ADIns e três ADCs perante o STF até setembro de $2019^{6}$, o judiciário sendo provocado para dar proteção aos direitos constitucionais supostamente violados pela reforma trabalhista.

Como oportunamente averba Konrad Hesse, mesmo uma ordem constitucional democrática necessita de direitos de defesa, na medida em que também a democracia não deixa de ser exercício de poder dos homens sobre homens, encontrando-se exposta às tentações do abuso de poder, bem como pelo fato de que mesmo num Estado de Direito os poderes públicos correm o risco de praticar injustiças. (HESSE, 1995, p. 131 apud SARLET, 2012, p.142)

Acima de tudo, os direitos fundamentais - na condição de direitos de defesa - objetivam a limitação do poder estatal, assegurando ao indivíduo uma esfera de liberdade e outorgandolhe um direito subjetivo que lhe permita evitar interferências indevidas no âmbito de proteção do direito fundamental ou mesmo a eliminação de agressões que esteja sofrendo em sua esfera de autonomia pessoal. (SARLET, 2012, p. 142)

Assim, verifica-se que boa parte dos direitos dos trabalhadores, positivados nos arts. $7^{\circ}$ a 11 de nossa Lei Suprema, são, na verdade, concretizações do direito de liberdade e do princípio da igualdade (ou da não discriminação), ou mesmo posições jurídicas dirigidas a uma proteção contra ingerências por parte dos poderes públicos e entidades privadas. É o caso, por exemplo, da limitação da jornada de trabalho (art. $7^{\circ}$, incs. XIII e XIV), do reconhecimento das convenções e acordos coletivos de trabalho (art. $7^{\circ}$, inc. XXVI), das normas relativas à prescrição (art. $7^{\circ}$, inc. XXIX), das proibições consignadas no art. $7^{\circ}$, incs. XXX a XXXIII, da igualdade de direitos entre o trabalhador com vínculo empregatício e o trabalhador avulso (art. $7^{\circ}$, inc. XXXIV), da liberdade de associação sindical (art. $8^{\circ}$ ), bem como do direito de greve $\left(\operatorname{art.} 9^{\circ}\right.$ ), apenas para ficarmos no âmbito das hipóteses mais evidentes. Ainda que a denominação de direito social (cuja pertinência não se pretende aqui colocar em dúvida), o fato é que estes dispositivos - de acordo com o critério da função desempenhada - contêm típicos direitos de defesa, situando-se, de acordo com abalizada doutrina, no âmbito das assim

\footnotetext{
${ }^{6}$ Disponível em: < https://www.migalhas.com.br/depeso/310236/reforma-trabalhista-adin-e-adc-lei-13467-17> Acessado em 09 maio 2020.
} 
denominadas liberdades sociais (direitos sociais negativos), tomando-se a expressão em sentido amplo, já que evidentemente (ao menos no que diz com o rol dos direitos sociais na nossa Constituição) não restrita a direitos típicos de liberdade. (SARLET, 2012, p.146)

Tomando como base a formulação de Alexy, os direitos à proteção podem ser sumariamente conceituados como posições jurídicas fundamentais que outorgam ao indivíduo o direito de exigir do Estado que este o proteja contra ingerências de terceiros em determinados bens pessoais. (ALEXY, 1994, p. 410). Nesse caso, as ações diretas de inconstitucionalidade, bem como as ações declaratórias de constitucionalidade estão sendo utilizadas como este meio de proteção dos direitos fundamentais dos trabalhadores, e o legislador infraconstitucional seria o denominado terceiro.

O reconhecimento de direitos à proteção pode ser reconduzido aos desenvolvimentos decorrentes da perspectiva jurídico-objetiva dos direitos fundamentais. Neste contexto, impõese que relembremos aqui a aceitação da ideia de que ao Estado, em decorrência do dever geral de efetivação dos direitos fundamentais, incumbe zelar - inclusive em caráter preventivo - pela proteção dos direitos fundamentais dos indivíduos, não só contra ingerências indevidas por parte dos poderes públicos, mas também contra agressões provindas de particulares e até mesmo de outros Estados, dever este que, por sua vez, desemboca na obrigação de adotar medidas positivas com vista a garantir e proteger de forma efetiva a fruição dos direitos fundamentais. (SARLET, 2012, p.158)

No que tange as violações cometidas por particulares é importante ressaltar que os trabalhadores encontram-se fragilizados no momento de pandemia e expostos aos riscos de contaminação, especialmente, os que se enquadram nas atividades essenciais. Quanto ao Estado brasileiro ao invés de dar a efetiva proteção aos direitos trabalhistas publica a medida provisória n 927 de 22 de março 2020, dispensando a realização de exames médicos ocupacionais durante o estado de calamidade pública. ${ }^{7}$

Segundo Alexy, o ponto de partida é a ideia de que os direitos fundamentais, enquanto direitos individuais em face do legislador são posições que, por definição, fundamentam deveres do legislador e restringem suas competências (ALEXY, 2008, p. 543). Sendo assim, do

\footnotetext{
${ }^{7}$ Art. 15. Durante o estado de calamidade pública a que se refere o art. $1^{\circ}$, fica suspensa a obrigatoriedade de realização dos exames médicos ocupacionais, clínicos e complementares, exceto dos exames demissionais.
} 
ponto de vista doutrinário, em tese, os direitos trabalhistas elencados na constituição não poderiam ser suprimidos pelo legislador infraconstitucional, fato este que não ocorreu com o trabalhador intermitente que não possui a garantia constitucional do salário mínimo, porque já estava à margem de efetiva proteção, o chamado, com emprego e sem trabalho.

Verifica-se que todos os direitos têm custos (no sentido de gerarem encargos para o Estado e a sociedade). José Casalta Nabais esclarece que os direitos sociais (como direitos a prestações) “concretizam-se em despesas públicas com imediata expressão na esfera de cada um dos seus titulares, uma esfera que se amplia na exata medida dessas despesas", ao passo que os direitos de cunho negativo, ainda de acordo com a lição do referido autor, "se materializam em despesas do estado com a sua realização e proteção, ou seja, em despesas com os serviços públicos adstritos basicamente à produção de bens públicos em sentido estrito". (NABAIS, 1990, p.22, apud SARLET, 2012, p.168)

O estado social precisa suportar os gastos públicos para garantir o mínimo existencial constitucionalmente estabelecido. O artigo $7^{\circ}$, inciso IV da Constituição Federal de 1988 estabelece como direito dos trabalhadores "salário mínimo, fixado em lei, nacionalmente unificado, capaz de atender a suas necessidades vitais básicas e às de sua família com moradia, alimentação, educação, saúde, lazer, vestuário, higiene, transporte e previdência social, com reajustes periódicos que lhe preservem o poder aquisitivo, sendo vedada sua vinculação para qualquer fim;"

Não podemos dar azo à ideia de que o desenvolvimento da nossa economia se faz pela via dos baixos salários e dos longos tempos de trabalho. Por outro lado, a convicção de que o dinamismo da economia se desenvolve, essencialmente, através de regimes amigáveis para os detentores de capital, empregadores e gestores. (FERNANDES, 2014, p.65)

Importa observar que os direitos sociais surgiram, embora resultado - como também no caso de boa parte dos direitos civis e políticos - a partir de processos de reivindicação gestados no âmbito dos movimentos sociais - como direitos assegurados por força mesmo da dignidade de cada pessoa individualmente considerada. Aliás, mesmo a liberdade de associação sindical e o direito de greve, não são tidos como direito exclusivamente coletivos, mas sim, direitos individuais de expressão coletiva (no sentido de uma interação entre a dimensão individual e a do grupo no qual se integra o indivíduo), visto que abrangem, no mais das vezes, a liberdade 
"negativa”, qual seja, a de não se associar ou de não participar de uma manifestação ou greve, embora a existência, como se sabe, de diferenciações importantes, a depender de cada ordem jurídica concretamente considerada. (SARLET, 2012, p.193)

Os direitos sociais foram arduamente conquistados ao longo da história do Brasil e do mundo, não podemos seja pela reforma trabalhista seja pelo período de calamidade pública, permitir tais violações ignorando a historicidade dos direitos trabalhistas.

O que há de ser devidamente enfatizado, é a circunstância de que direitos humanos e fundamentais, sejam eles civis e políticos, sejam eles sociais, econômicos e culturais (assim como ambientais, em certo sentido), são sempre direitos referidos, em primeira linha, à pessoa individualmente considerada, e é a pessoa (cuja dignidade é pessoal, individual, embora socialmente vinculada e responsiva) o seu titular por excelência. (SARLET, 2012, p.194)

No âmbito dos direitos fundamentais, por vinculação da argumentação "à lei" deve ser compreendida urna vinculação ao texto das disposições de direitos fundamentais e à vontade do legislador constituinte (ALEXY, 2008, p. 552). Desse modo as normas infraconstitucionais devem respeitar o que dispõe a Constituição Federal.

Na medida em que o legislador constituinte tenha tomado decisões na forma de regras, elas são vinculantes, a não ser que seja possível introduzir razões constitucionais suficientes contra essa vinculação (ALEXY, 2008, p. 554). Ou seja, um possível descumprimento de norma constitucional só é admitido se a exceção estiver prevista também na Constituição, sendo assim, as normas constitucionais são vinculantes e não admitem relativização por norma infraconstitucional.

Embora a Constituição não possa, por si só, realizar nada, ela pode impor tarefas. A Constituição transforma-se em força ativa se essas tarefas forem efetivamente realizadas, se existir a disposição de orientar a própria conduta segundo a ordem nela estabelecida, se, a despeito de todos os questionamentos e reservas provenientes dos juízos de conveniência, se puder identificar a vontade de concretizar essa ordem. (HESSE, 1991, p.4)

Nesse sentido a Constituição teria, além da força vinculante, uma força ativa em realizar as normas nela estabelecida. O legislador infraconstitucional ao criar o trabalhador intermitente, 
por exemplo, deveria prever meios de concretizar a garantia do salário mínimo ao invés de só estabelecer o pagamento pelo tempo efetivamente trabalhado.

Pelo que fora exposto, os direitos fundamentais catalogados do artigo $5^{\circ}$ ao $17^{\circ}$ da Constituição Federal, dentre eles os direitos trabalhistas, possuem limites que devem ser observados pelo legislador infraconstitucional, sob pena de se negar a efetividade e a vontade do constituinte. Não se pode negar a força vinculante da Constituição no ordenamento jurídico brasileiro, qualquer tentativa de violação dará ensejo às ações de inconstitucionalidade no chamado guardião da Constituição.

\section{DIREITOS DA PERSONALIDADE}

Os direitos da personalidade precisam ser desmistificados no que tange a sua conceituação e a sua abrangência. Hodiernamente, não se admite a concepção de que os direitos da personalidade estão em um rol taxativo, isolado, no Código Civil Brasileiro, adota-se a teoria pluralista dos direitos da personalidade em que a violação de direitos trabalhistas, de forma reflexa, poderá ensejar violação aos direitos da personalidade dos trabalhadores.

Em sentido didático, pode-se dizer que "assim como os direitos da personalidade estão para o Código Civil, os direitos fundamentais estão para a Constituição Federal” (TARTUCE, 2014, p. 122), sendo que o rol dos direitos da personalidade previsto nos artigos 11 a 21 do Código Civil é meramente exemplificativo (DINIZ, 2012, p. 139).

A dignidade da pessoa humana é um atributo inerente a qualquer pessoa, tornando esta destinatária de respeito e proteção por parte do Estado e das outras pessoas. É um dos princípios basilares dentro do ordenamento jurídico pátrio, que serve como sustentáculo para todas as normas, buscando impedir que o ser humano seja alvo de situações desumanas ou degradantes, bem como garantindo o direito de acesso a condições existenciais mínimas. 
Caracterizando-se por ser um direito tão natural e imprescindível quanto o direito à vida, a dignidade da pessoa humana é um valor construído durante todo o decorrer da história. (SIQUEIRA, 2019, p.305)

Sendo assim, os direitos da personalidade podem ser entendidos como uma decorrência lógica da dignidade da pessoa humana e por consequência também estariam protegidos como direitos fundamentais, assim como os direitos trabalhistas.

Nesse aspecto, em que pese os direitos da personalidade estejam evidenciados nos artigos 11 a 21 do Código Civil Brasileiro, por decorrência lógica da dignidade da pessoa humana, seria possível elevar os direitos da personalidade como direitos fundamentais.

Ademais, como sustenta Alexy, uma teoria material dos direitos fundamentais como teoria normativa geral é possível apenas na forma de uma teoria dos princípios (ALEXY, 2008, p.561). Não se faz necessária uma inserção explicita dos direitos da personalidade no catálogo de direitos fundamentais na Constituição Federal.

A Constituição Federal de 1988 traz expressamente em seu artigo $5^{\circ}$, caput e seus incisos, direitos fundamentais como a vida, liberdade, igualdade, privacidade, intimidade, honra e imagem, dentre outros, que reforçam o vínculo constitucional com os direitos da personalidade. Nesse sentido podemos afirmar que os direitos da personalidade estão intimamente ligados à dignidade da pessoa humana.

Os direitos da personalidade consagram-se, na garantia da dignidade da pessoa humana e são direitos subjetivos de ordem física, psíquica e moral. A Constituição Federal (art. 5º, incisos V e X), o Código Civil (arts. 11 ao 21) e a Consolidação da Leis do Trabalho (art. 223A) listam, a título exemplificativo, os direitos da personalidade, dentre eles: direito à honra, à imagem, à intimidade, à liberdade de ação, à autoestima, à sexualidade, à saúde, ao lazer e outros mais. (SILVA, 2019, p. 49)

Tepedino esclarece que a tutela da personalidade é dotada de elasticidade. "Elasticidade no sentido de abrangência de tutela que faz incidir a salvaguarda da dignidade em todas as situações, previstas ou não, em que esgrimida a personalidade tida como valor máximo do ordenamento." (TEPEDINO, 2009, p.91) 
Tratar dos direitos da personalidade de modo regulamentar, com normas casuísticas, fechadas, é extremamente perigoso. Isso por três razões principais. Primeiro, porque são direitos de índole constitucional, cuja proteção não pode ser indevidamente limitada pelo legislador ordinário. Segundo, porque as situações fáticas em que se configura a ameaça aos direitos da personalidade são amplíssimas e têm se expandido continuamente em face das novas tecnologias. Terceiro, não é incomum que a proteção dos direitos da personalidade colida com a tutela de outros direitos de ordem constitucional. Nesses casos, as normas fechadas estabelecidas pelo legislador ordinário perdem sentido, exigindo que o intérprete proceda à necessária ponderação entre os interesses conflitantes. (SCHREIBER, 2013, p. 222)

Lamentavelmente, cada vez mais a dignidade da pessoa humana (de alguns humanos mais do que outros) é violada e desprotegida, seja pelo aumento assustador da violência contra a pessoa, seja pela carência social, econômica e cultural e grave comprometimento das condições existenciais mínimas para uma vida com dignidade e, neste passo, de uma existência com sabor de humanidade (SARLET, 2015, p. 99). Frisa-se que a reforma trabalhista e a flexibilização das normas trabalhistas em razão da pandemia, de maneira reflexa, atinge a dignidade dos trabalhadores e até os direitos da personalidade dos atores que permanecem trabalhando nas atividades essenciais, principalmente. Isso, sem contar aqueles que tiveram as suas jornadas e salários reduzidos, por acordo individual de trabalho, sem a participação do seu sindicato de classe, conforme preconizou a Medida Provisória 936/20 ${ }^{8}$, hoje convertida na Lei n. $14.020 / 2020^{9}$.

O direito fundamental a uma vida digna deveria ser absoluto para evitar a sua violação, no entanto, Robert Alexy entende que a dignidade da pessoa humana é passível de ponderação quando em rota de colisão com outros bens jurídicos de estatura constitucional (ALEXY, 1994, p. 94 ss). Aqui não se nota algum direito que seja capaz de relativizar a dignidade da pessoa frente aos direitos trabalhistas.

\footnotetext{
${ }^{8}$ Vide ADI no 6363. Disponível em: <http://portal.stf.jus.br/processos/detalhe.asp?incidente=5886604 > Acesso em 13 jul. 2020.

${ }^{9}$ Art. $7^{\circ}$ Durante o estado de calamidade pública a que se refere o art. $1^{\circ}$ desta Lei, o empregador poderá acordar a redução proporcional de jornada de trabalho e de salário de seus empregados, de forma setorial, departamental, parcial ou na totalidade dos postos de trabalho, por até 90 (noventa) dias, prorrogáveis por prazo determinado em ato do Poder Executivo, observados os seguintes requisitos:
} 
Deste modo os direitos da personalidade estão enraizados no ordenamento jurídico brasileiro, seja na sua origem pátria, Código Civil, como também na Constituição Federal e por fim, na Consolidação das Leis Trabalhistas. Em que pese o largo arcabouço jurídico normativo, nota-se que o legislador infraconstitucional, como foi mencionado, não garante os direitos da personalidade ao trabalhador intermitente quando não se garante o mínimo existencial a título de salário. Tal qual, não garante aos demais trabalhadores, ao entender passível a exclusão do diálogo social, do seu representante de classe, o Sindicato.

\section{FLEXIBILIZAÇÃO OU PRECARIZAÇÃO DAS NORMAS TRABALHISTAS NO MOMENTO DE PANDEMIA}

A reforma trabalhista sancionada em 13 de julho de 2017 trouxe a modalidade do contrato intermitente, que até então não existia na legislação trabalhista brasileira. Assim, desde 11 de novembro de 2017, data da entrada em vigor do novo diploma legal, empresas podem efetuar contrato por escrito, com funcionários para trabalhar esporadicamente, e pagá-los somente pelo lapso em que prestaram seus préstimos. (SILVA, 2019, p.46)

Vólia Bomfim Cassar, aduz que, esta espécie de contrato gera insegurança econômica ao trabalhador, pois não há garantia de quantidade mínima de trabalho por mês, nem previsibilidade de novo trabalho, o que fere de morte os princípios da segurança jurídica e a proteção ao trabalhador (CASSAR, 2017, p. 600). E, por consequência, não garante o salário mínimo.

O problema do contrato de trabalho intermitente, ao contrário do seu conceito, é muito claro: há relação de emprego, formalmente registrada em CTPS, mas sem garantia do pagamento de nenhum valor ao final de um mês (ALVES, 2019, p.62). Sendo intitulado de empregado sem trabalho, já que formalmente é um empregado, no entanto não há garantia de continuidade o que prejudica o trabalho. 
Sobre os aspectos abordados, é imperiosa a reflexão se essa nova modalidade contratual advinda com a reforma trabalhista estaria violando direitos fundamentais do trabalhador, dentre eles, os direitos da personalidade.

A análise aqui empreendida será restrita ao tema do trabalho intermitente e poderia ser perfeitamente resumida em um único ponto: a necessidade de pagamento de salário mínimo mensal ao trabalhador intermitente independentemente de ser ou não chamado ao trabalho e de quantas horas dispõe ao contrato, respeitado o limite constitucional. Tal medida tem respaldo na melhor interpretação do disposto no artigo $7^{\circ}$, incisos IV e VII da CF, que deve ser feita à luz de princípios também constitucionais como valorização social do trabalho e dignidade da pessoa humana. A compreensão é simples: se o trabalhador intermitente for remunerado conforme preceitua a Constituição da República (e não conforme historicamente decidia o $\mathrm{TST}^{10}$ ) não haverá precarização na contratação, pois o patamar civilizatório mínimo estará preservado, visto o efeito expansionista circular do salário, que se irradiará para outros direitos (férias, $13^{\circ}$ salário, INSS, FGTS, etc.). (ALVES, 2019, p.64/65)

A previsão legal do contrato de trabalho intermitente sem a garantia do salário mínimo fere toda a ordem constitucional tão defendida na efetividade dos direitos fundamentais. A doutrina já se encontrava pacificada sobre a efetividade dos direitos fundamentais e a imposição ao legislador infraconstitucional dos limites colocados pelo constituinte. No entanto, a lei $\mathrm{n}^{\mathbf{o}}$ 13.467/2017, ignora toda a técnica jurídica e faz uma ruptura indiferente a tudo que havia sido construído em termos de efetividade de direitos fundamentais.

A identificação dos limites dos direitos fundamentais constitui condição para que se possa controlar o seu desenvolvimento normativo, partilhado com o legislador ordinário. (SARLET, 2012, p.365). Nesse sentido o legislador infraconstitucional não foi capaz de observar a garantia do salário mínimo para esta espécie de trabalhador, como resultado às inúmeras ações diretas de inconstitucionalidade pendentes de julgamento no Supremo Tribunal Federal.

\footnotetext{
${ }^{10} \mathrm{O}$ TST firmou o entendimento de que o salário mínimo legalmente fixado leva em conta o padrão ordinário de disponibilidade de trabalho, de modo que, em jornadas (e disponibilidades semanais) menores, possível é a contraprestação mínima proporcional.
} 
Em relação ao momento da Pandemia, o ministro Ives Gandra do Tribunal Superior do Trabalho, em uma entrevista afirma que: "na área trabalhista, juízes exigem uma proteção absoluta ao trabalhador, como se nem se pudesse flexibilizar a legislação ou fosse possível a negociação coletiva, com as necessárias assembleias gerais, em tempo de isolamento horizontal. A proteção da lei e da Justiça deve ser proporcional aos efeitos da pandemia, e as decisões judiciais devem se pautar pela lucidez do possível.” (MARTINS, 2020). Ou seja, o ministro critica a área trabalhista por não permitir a flexibilização, o que não corresponde com a edição das diversas medidas provisórias que dispensam os trabalhadores da realização de exames médicos ocupacionais, por exemplo.

As medidas provisórias 926 e 936 de 2020, que foram editadas para manutenção dos empregos no período de pandemia, já foram alvos das ações diretas de inconstitucionalidade $\mathrm{n}^{\circ}$ 6363 e 6342 no supremo tribunal federal. A ADI 6342, foi proposta e, liminarmente, determinou a suspensão da eficácia dos artigos 29 e 31 da medida provisória n ${ }^{\circ} 927$ de $2020 .{ }^{11}$

O artigo 29 disciplina que os casos de contaminação pelo novo coronavírus não seria considerado como doença ocupacional, exceto comprovação de nexo de causalidade. No entanto, no atual cenário, não há como identificar onde se deu a contaminação, o que torna impossível a comprovação do nexo causal. Além do que, é ônus do empregador de atividade essencial, que mantém os trabalhadores em atividade, adotar as medidas necessárias para prevenção da contaminação.

Sendo assim, desde 29/04/2020, estando suspensa a eficácia deste dispositivo, é plenamente possível considerar a Covid 19 como doença ocupacional, o que reforça o argumento para que empregadores mantenham seus empregados em casa, evitando uma possível responsabilidade em caso de contágio.

O artigo 31 da medida provisória n ${ }^{\circ} 927$ de 2020 se refere a atuação da fiscalização por parte dos auditores fiscais do trabalho. Em um momento tão peculiar da história da humanidade, os trabalhadores, hipossuficientes, ficariam desprotegidos ante a falta de fiscalização, incentivando os empregadores a violarem normas trabalhistas já que não teriam nenhuma

${ }^{11}$ BRASIL. Supremo Tribunal Federal. Ação direta de inconstitucionalidade $n^{\circ}$ 6363. Processo $\mathrm{n}^{\circ} 0089460$ 11.2020.1.00.0000. Disponível em: < http://portal.stf.jus.br/processos/detalhe.asp?incidente=5886604 > Acesso em 11 maio 2020. 
penalidade a ser aplicada. Acertadamente, o Supremo Tribunal Federal, suspendeu a eficácia deste dispositivo, o que permite que os auditores fiscais do trabalho, façam as devidas fiscalizações.

Acredita-se que o Estado deve agir fornecendo mecanismos para que trabalhadores e empregadores enfrentem este período indeterminado de calamidade pública. No entanto, o Supremo Tribunal Federal, como guardião da Constituição Federal, não pode se eximir de reprimir normas de caráter inconstitucional. Nessa perspectiva o poder executivo edita várias medidas de caráter normativo e o Poder Judiciário, no controle constitucional, suspende ou não sua eficácia.

Noemia Porto, presidente da Anamatra, afirmou que, em situações excepcionais, como pandemia ou estado de sítio, a Constituição deve ser observada. "A Constituição Federal não é um problema, ela é parte da solução porque ela funciona em tempos de normalidade e de crise como uma rede de proteção das garantias, de que o nosso rumo será retomado em algum momento", disse. (PORTO, 2020) Ou seja, mesmo nos momentos de crise, não se pode permitir violação à constituição federal. Ademais quando alguns dispositivos já foram construídos para aplicação em momentos de crise, como é o caso da redução de salário e jornada mediante acordo ou convenção coletiva.

A revisão das leis laborais- no sentido de sua "flexibilização", isto é, no sentido da rarefacção dos dispositivos limitadores do poder de decisão de quem chefia ou gere as organizações, e também no sentido do seu "embaratecimento", ou seja, da redução de vantagens econômicas para os trabalhadores - surge, assim, invariavelmente, na primeira linha dos recursos para a resolução de dificuldades econômicas e sociais. (FERNANDES, 2014, p.60)

Entende-se que as normas trabalhistas podem ser flexibilizadas e relativizadas em razão da pandemia, no entanto, o mínimo constitucional deve ser garantido, sob pena de se caracterizar a precarização, o que deve ser repudiado pelos pesquisadores do direito. 


\section{CONCLUSÕES}

Os teóricos constitucionalistas Sarlet, Alexy e Hesse, discorreram por várias páginas considerando a importância dos direitos fundamentais. Fizeram conceituações, classificações, argumentações sobre a efetividade, limitações ao legislador infraconstitucionais, enfim, obras de leitura elementar quando se fala em direitos fundamentais.

Em que pese algumas discrepâncias, sobretudo a crítica de Sarlet sobre o excesso de direitos e o perigo da vulgarização, todos coadunam da importância que deve ser dada aos direitos fundamentais seja por parte do Estado seja pelo legislador.

No entanto, a reforma trabalhista, pontualmente, o contrato intermitente, está na contramão em relação a tudo que era pacífico em termos de constituição e direitos fundamentais. Favorável ou não, é inegável o direito fundamental ao salário mínimo do artigo $7^{\circ}$, inciso VII da Constituição Federal, tendo em vista que está dentro do catálogo encampado por Sarlet.

Alexy sustenta que normas de ordem constitucional seriam vinculantes, não cabendo ao legislador infraconstitucional trazer tal limitação ou exceção, aliás, a exceção teria que estar expressa no próprio texto constitucional, o que não ocorre em relação ao salário mínimo, especificamente.

Para Konrad Hesse, a Constituição Federal possui uma força ativa que pode impor tarefa e orientar as ações estatais. Nesse sentido, caberia ao legislador infraconstitucional trazer para a realidade a garantia constitucional do salário mínimo ao trabalhador intermitente o que não o fez, ignorou completamente a força normativa da constituição.

Sobre os direitos da personalidade, é inegável a sua existência e correlação com os direitos fundamentais, precipuamente, a dignidade da pessoa humana. Nessa vertente, a violação ao mínimo existencial do trabalhador intermitente, sem sombra de dúvidas, acarreta violação aos direitos fundamentais, bem como direitos da personalidade. Isso ficou mais evidenciado neste período de pandemia, quanto aos intermitentes. 
Em relação às normas editadas no momento da pandemia que impactam nas relações de trabalho é imperioso que estas observem os limites constitucionais. É inegável o momento excepcional, mas utilizar-se desse argumento para violar direitos da classe obreira é um ato desumano.

A fim de evitar tais violações, o Supremo Tribunal Federal, acertadamente, vem atuando e suspendendo efeitos de medidas que considera inconstitucional, embora ainda seja insuficiente, como foi exposto em relação à redução de salário e jornada, sem a participação do Sindicato da categoria. Fazemos parte de um estado democrático de direito e a constituição deve ser a orientação a ser seguida pelos independentes e harmônicos três poderes.

Por fim, a título de reflexão, não se pode permitir, seja no contrato de trabalho intermitente ou quaisquer outros da relação de emprego, que no momento de pandemia, as relações de trabalho sejam precarizadas. Admite-se uma flexibilização das normas ante a excepcionalidade do tempo, no entanto, a Constituição Federal deve ser observada como patamar mínimo que garanta os direitos fundamentais.

\section{REFERÊNCIAS BIBLIOGRÁFICAS}

ALEXY, Robert. Teoria dos Direitos Fundamentais. Tradução de Viroílio Afonso da Silva. São Paulo: Malheiros Editores. 2008

ALVES, Amauri Cesar. TRABALHO INTERMITENTE E OS DESAFIOS DA CONCEITUAÇÃO JURÍDICA. Revista Eletrônica do Tribunal Regional do Trabalho da

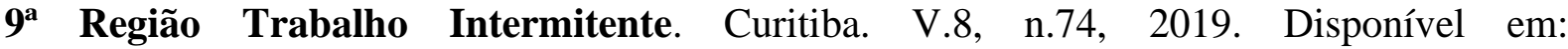
http://www.mflip.com.br/pub/escolajudicial/?numero=74\&edicao=10990\#page/41 Acesso em: 6 dez. 2019.

BOBBIO, Norberto, 1909- A era dos direitos / Norberto Bobbio; tradução Carlos Nelson Coutinho; apresentação de Celso Lafer. — Nova ed. — Rio de Janeiro: Elsevier, 2004.

BRASIL. Constituição (1988). Constituição da República Federativa do Brasil. Brasília, DF: Senado Federal: Centro Gráfico, 1988.

BRASIL. Decreto-Lei n ${ }^{\circ}$ 5.452/1943, de 1 de maio de 1943. Aprova a Consolidação das Leis do Trabalho. Brasília, DF: Presidente da Republica, 2017. Disponível em: http://www.planalto.gov.br/ccivil_03/Decreto-Lei/Del5452.htm Acesso em: 07 dez. 2019. 
BRASIL. Lei 10.406/2002, de 10 de janeiro de 2002. Institui o Código Civil. Brasília, DF: Presidente da República, 2002. Disponível em: http://www.planalto.gov.br/ccivil_03/LEIS/2002/L10406.htm Acesso em: 07 dez. 2019.

BRASIL. Supremo Tribunal Federal. Ação direta de inconstitucionalidade $n^{\circ} 6363$. Processo $n^{\circ}$ 0089460-11.2020.1.00.0000. Disponível em: http://portal.stf.jus.br/processos/detalhe.asp?incidente=5886604 Acesso em 11 maio 2020.

CASSAR, Vólia Bomfim. Direito do Trabalho de acordo com a Lei 13.467/2017, 14. Ed. São Paulo: Método, 2017.

DINIZ, Maria Helena. Curso de direito civil brasileiro, teoria geral do direito civil. 29. ed. São Paulo: Saraiva, 2012, v. 1.

FERNANDES, Antônio Monteiro. A reforma laboral de 2012, observações em torno da lei n. 23/2012. Revista o tempo de Trabalho: jurisdição do trabalho e da Empresa. Lisboa: centro de estudos judiciários. 2014.2 Disponível em: http://www.cej.mj.pt/cej/recursos/ebooks/trabalho/o_tempo_de_trabalho.pdf Acesso em 11 maio 2020.

HESSE, Konrad. A Força Normativa da Constituição, Porto Alegre: Fabris, 1991.

MARTINS, Ives Gandra da Silva. Tempos Difíceis. [entrevista concedida a] Rafa Santos. Revista Consultor Jurídico, 26 de abril de 2020, 7h22. Disponível em: https://www.conjur.com.br/2020-abr-26/entrevista-ives-gandra-silva-martins-filho-ministrotst Acesso em 09 maio 2020.

PORTO, Noemia. Advogados discutem reflexo da pandemia nas relações de trabalho. [webinar diário]. Revista Consultor Jurídico, 6 de abril de 2020, 15h46. Disponível em: https://www.conjur.com.br/2020-abr-06/advogados-discutem-reflexo-pandemia-relacoestrabalho Acesso em 11 maio 2020.

SARLET, Ingo Wolfgang. A Eficácia dos Direitos Fundamentais: Uma Teoria Geral dos Direitos Fundamentais na Perspectiva Constitucional. 11. ed. rev. atual. Porto Alegre: Livraria do Advogado Editora, 2012.

SARLET, Ingo Wolfgang. Dignidade da pessoa humana: notas em torno da discussão sobre o seu caráter absoluto ou relativo na ordem jurídico-constitucional. In: Dignidade humana e direitos sociais e não-positivismo. Org.: Robert Alexy, Narciso Leandro Xavier Baez, Rogério Luiz Nery da Silva. Florianópolis: Qualis 2015.

SCHREIBER, Anderson. Direitos da Personalidade. 2.ed. São Paulo: Atlas, 2013.

SIQUEIRA, Dirceu Pereira; RUIZ, Ivan Aparecido. Acesso à justiça e os direitos da Personalidade. 1. ed. Birigui-SP: Editora Boreal, 2015.

SIQUEIRA, Dirceu, LAZARETTI, Bruna. Eutanásia social e os direitos da personalidade: uma leitura constitucional crítica. Argumenta Journal Law, Jacarezinho - PR, Brasil, n. 30, 2019, p. 297-329. 
SILVA, Leda Maria Messias da, ALVÃO, Leandra Cauneta. A escravidão legalizada: contrato intermitente e as novas regras que vulnerabilizam a relação de emprego e afrontam os direitos da personalidade. Revista Eletrônica do Tribunal Regional do Trabalho da $9^{a}$ Região Trabalho Intermitente. Curitiba. V.8, n.74, 2019. Disponível em: http://www.mflip.com.br/pub/escolajudicial/?numero=74\&edicao=10990\#page/41 Acesso em: 6 dez. 2019.

SCHREIBER, Anderson. Direitos da Personalidade. 2.ed. São Paulo: Atlas, 2013.

TARTUCE, Flávio. Direito civil: lei de Introdução e parte geral. 10. ed. rev., atual. e ampl. Rio de Janeiro: Forense; São Paulo: Método, 2014.

TEPEDINO, Gustavo apud CANTALI, Fernanda Borghetti. Direitos da Personalidade: disponibilidade relativa, autonomia privada e dignidade. Porto Alegre: Livraria do Advogado, 2009.

Data de Submissão: 13/07/2020

Data de Aceite: 06/10/2020 